\title{
ALTERNATIF KEBIJAKAN OPERASIONAL PENGGUNAAN SMS GATEWAY PADA RUJUKAN KEGAWATDARURATAN MATERNAL
}

\author{
Ela Rohaeni*Norma Mardiani**
}

\begin{abstract}
ABSTRAK
Kematian ibu adalah kematian seorang wanita terjadi saat hamil, bersalin, atau 42 hari setelah persalinan dengan penyebab yang berhubungan langsung atau tidak langsung terhadap persalinan. Dalam rangka mempercepat penurunan angka kematian ibu salah satunya adalah dengan memperkuat sistem rujukan. Dalam hal ini pengoptimalan kebijakan SMS Gateway. Tujuan penelitian ini adalah menyusun alternatif kebijakan operasional penggunaan SMS Gateway pada rujukan kegawatdaruratan maternal di Dinas Kesehatan Kabupaten Cirebon Tahun 2017. Penelitian ini merupakan penelitian kualitatif dengan pendekatan konfirmatori, teknik pengumpulan data dengan menggunakan teknik purposive sampling, untuk memperoleh hasil dengan pemahaman mendalam tentang topik penelitian. Informan kunci dalam penelitian ini adalah bidan pelaksana berjumlah 6 orang pelaksana sedangkan informan pendukung yaitu kepala puskesmas, kepala bagian Yankes, kepala Dinas Kesehatan Kabupaten Cirebon. Temuan penelitian ini adalah kebijakan yang ada saat ini yaitu mengenai aspek penting dalam upaya menurunkan angka kematian ibu namun ditemukan dalam pengaplikasiannya belum optimal. Alternatif kebijakan operasional pada rujukan kegawatdaruratan maternal di Dinas Kesehatan Kabupaten Cirebon yaitu pembuatan SK Kepala Dinas tentang petunjuk teknis sistem SMS Gateways rujukan pelayanan kesehatan dan Standar Prosedur Operasional SMS Gateway rujukan kegawatdaruratan maternal dan neonatal.
\end{abstract}

Kata kunci : Kebijakan Operasional, SMS Gateway, Rujukan, Kegawatdaruratan Maternal

\begin{abstract}
Maternal death is the death of a woman occurs during pregnancy, childbirth, or 42 days after delivery with a cause that is directly or indirectly related to labor. In order to accelerate the decline in maternal mortality one of them is by strengthening the referral system. In this case the SMS Gateway policy optimization. The purpose of this research is to formulate operational policy alternatives of SMS Gateway utilization on maternal emergency referral in Cirebon District Health Office 2017. This research is a qualitative research with confirmatory approach data collection technique using purposive sampling technique, to obtain result with deep understanding about research topic. Key informants in this research are midwife implementer is 6 executor while supporting informant is head of puskesmas, head of Yankes department, head of health office of Cirebon regency. The findings of this study are that the existing policy has been about important aspects in efforts to reduce maternal mortality but found in its application not yet optimal. Alternative operational policy on maternal emergency referral at Cirebon District Health Office is making SK Head of Service about technical guidance of SMS Gateways system of referral of health service and Standard of Operational Procedure SMS Gateway referral of maternal and neonatal emergency.
\end{abstract}

Keywords : : Operational Policy, SMS Gateway, Referral, Maternal Emergency

\footnotetext{
*Staff Pengajar Program Studi D3 Kebidanan STIKes Cirebon

** Staf Pengajar Program Studi D3 Kebidanan STIKes Cirebon
} 


\section{PENDAHULUAN}

Kematian ibu adalah kematian seorang wanita yang terjadi saat hamil, bersalin, atau 42 hari setelah persalinan dengan penyebab yang berhubungan langsung atau tidak langsung terhadap persalinan. Organisasi kesehatan tingkat dunia, World Health Organization (WHO) memperkirakan 800 perempuan meninggal setiap harinya akibat komplikasi kehamilan dan proses kelahiran. Sekitar 99\% dari seluruh kematian ibu terjadi di negara berkembang. ${ }^{1}$

Sekitar $80 \%$ kematian maternal merupakan akibat meningkatnya komplikasi selama kehamilan, persalinan dan setelah persalinan. Menurut laporan WHO yang telah dipublikasikan pada tahun 2014 Angka Kematian Ibu (AKI) di dunia mencapai angka 289.000 jiwa. Di mana terbagi atas beberapa Negara, antara lain Amerika Serikat mencapai 9300 jiwa, Afrika Utara 179.000 jiwa dan Asia Tenggara 16.000 jiwa. Untuk AKI di negaranegara Asia Tenggara diantaranya Indonesia mencapai 214 per 100.000 kelahiran hidup, Filipina 170 per 100.000 kelahiran hidup, Vietnam 160 per 100.000 kelahiran hidup, Thailand 44 per 100.000 kelahiran hidup, Brunei 60 per 100.000 kelahiran hidup, dan Malaysia 39 per 100.000 kelahiran hidup. ${ }^{1}$

Angka kematian Ibu di provinsi Jawa Barat pada tahun 2013 berjumlah sebanyak 216 orang dengan sebaran di Kabupaten Cirebon sebanyak 33 orang, Kabupaten Tasikmalaya 35 orang, Kabupaten Garut 57 orang dan Kota Cianjur 14 orang. ${ }^{2}$ Tahun 2014, kematian ibu di Provinsi Jawa Barat mengalami peningkatan menjadi sebanyak 230 orang. ${ }^{2}$ Angka tersebut masih cukup jauh dari target AKI di Indonesia, mengingat target AKI di Indonsia pada tahun 2015 adalah 102 kematian per 100.000 kelahiran hidup. $^{3}$

AKI di Kabupaten Cirebon pada tahun 2011 sebanyak 222 orang (0,095\%) dari 232.734 persalinan dan yang mengalami komplikasi sebanyak 26.125 orang, tahun 2012 sebanyak 240 orang $(0,106 \%)$ dari 225.939 persalinan dan yang mengalami komplikasi sebanyak 33.908 orang, tahun 2013 mengalami penurunan menjadi sebanyak 201 orang $(0,0086 \%)$ dari 231.276 persalinan dan yang mengalami komplikasi sebanyak 40.732 orang. Pada tahun 2014 AKI meningkat menjadi sebanyak 233 orang $(0,1 \%)$ dari 232.143 persalinan dan yang mengalami komplikasi sebanyak 41.107 orang. ${ }^{4}$ Fenomena penurunan AKI pada tahun 2013 dan peningkatan AKI tahun 2014 di Kabupaten Cirebon berhubungan dengan pemilihan pertolongan persalinan di sarana kesehatan atau menggunakan pertolongan tenaga kesehatan. Selain itu kesulitan akses terhadap pelayanan kesehatan menyebabkan rendahnya pemanfaatan pelayanan kesehatan. Akses biaya juga mempengaruhi sehingga masyarakat masih banyak yang beranggapan bahwa bila persalinan ditolong oleh bidan biayanya mahal sedangkan bila ditolong oleh dukun bisa membayar berapa saja. Kondisi sosial ekonomi dan pengetahuan mempengaruhi preferensi ibu hamil untuk melakukan proses persalinan menggunakan dukun. ${ }^{5,6,7}$

Sistem rujukan ibu melahirkan atau ibu bersalin di Indonesia telah berkiblat pada sistem rujukan nasional yang bersifat berjenjang. Jenjang rujukan sudah dibagi menjadi beberapa bagian baik dalam kota maupun lintas kota. ${ }^{6}$ Alur rujukan pasien diatur dalam program Jaminan Kesehatan Nasional (JKN) melalui program SMS Gateway. Program SMS Gateway memberikan manfaat yang sangat besar bagi para bidan yaitu meningkatnya pengetahuan dan keterampilan dalam menangani kasus kegawatdaruratan dan jumlah pasien bersalin mengalami peningkatan sebesar 15\% pada tahun 2013. Kendala yang dihadapi dalam program tersebut di puskesmas antara lain SMS Gateway dinilai kurang efektif untuk pengiriman informasi rujukan, belum adanya kerjasama tim sehingga kesulitan dalam melakukan konsultasi pada kasus gawat darurat. ${ }^{8,9}$ Kedatangan era teknologi informasi dan komunikasi tidak dapat lepas dari peran serta layanan internet yang semakin melekat erat dengan gaya hidup dan kebutuhan kita saat ini, seiring itu pula teknologi penyediaan layanan jaringan internet terus berkembang, tujuannya adalah untuk selalu berinovasi memberikan pelayanan terbaik terhadap segala kebutuhan kita akan akses informasi yang aman dan lebih efisien. 
Salah satu teknologi yang paling banyak digunakan adalah pemanfaatan teknologi SMS Gateway. ${ }^{10,11,12}$

SMS Gateway saat ini menjadi sebuah terobosan baru di dunia kesehatan khususnya di Dinas Kesehatan Kabupaten Cirebon. Sistem informasi rujukan ibu hamil berbasis SMS Gateway yang telah diterapkan di Dinas Kesehatan tersebut bertujuan untuk meningkatkan pelayanan gawat darurat dan memperkuat jejaring sistem rujukan yang efektif dan efisien bagi bidan desa dan ibu hamil di wilayah Kabupaten Cirebon. Dengan demikian, semakin banyaknya bidan desa dan ibu hamil maka kebutuhan akan sistem informasi dan telekomunikasi yang dapat mengirimkan data dengan jumah yang besar dan dengan kecepatan tinggi serta terhindar dari gangguan-gangguan seperti trafik yang padat sehingga menyebabkan delay pada saat transfer data kepada tujuan sangat dibutuhkan. 13,14,15 Mengingat keselamatan ibu hamil dan bayi adalah prioritas utama bagi pelayanan kesehatan yang ada di Cirebon.

Intervensi program SMS Gateway di Kabupaten Cirebon dari aspek proses telah menunjukkan peningkatan yang menggembirakan, yaitu puskesmas sudah menjalankan program SMS Gateway memberikan mentoring/pendampingan kepada puskesmas yang belum melaksanakan program SMS Gateway, tetapi dari aspek keluaran belum menunjukkan hasil yang signifikan yaitu masih tingginya AKI dan AKB. Dari hasil wawancara yang dilakukan oleh peneliti di Puskesmas yang telah menjalankan program SMS Gateway diperoleh informasi bahwa terdapat banyak perubahan baik dari segi pelayanan dan juga tata kelola, diantaranya Standar Operasional Prosedur (SOP) dalam sistem rujukan, pencatatan dan pelaporan serta standar pelayanan.

\section{METODE PENELITIAN}

Jenis penelitian ini adalah penelitian kualitatif dengan pendekatan deskriptif yaitu berusaha mendapatkan informasi selengkap mungkin mengenai kebijakan SMS Gateway. Informan kunci dalam penelitian ini adalah: bidan dan bidan pelaksana dan informan pendukung dalam penelitian ini adalah Kepala Dinas, Kepala Puskesmas dan Kabag Yankes.

Penelitian ini dilaksanakan di Kabupaten Cirebon, penelitian ini dilaksanakan pada bulan Januari-Februari 2017. Instrumen penelitian adalah peneliti itu sendiri dengan menggunakan alat bantu, yaitu panduan wawancara, cheklist, tape recorder video kamera, dan buku catatan.

Teknik pengumpulan data dalam penelitian ini adalah dengan menggunakan teknik purposive sampling. Pengumpulan data dalam bentuk tertulis mulai dari pelaksanaan pengumpulan data sampai hasil analisis berupa informasi dari pengumpulan data tersebut.

Data yang terkumpul dari hasil rekaman wawancara mendalam selanjutnya dibuat transkrip, lalu disederhanakan dalam bentuk matriks kemudian dicari kata kuncinya. Namun tetap peneliti menggunakan teknik analisa secara umum pada pendekatan kualitatif yaitu : setelah semua data terkumpul dan diolah, maka tahapan selanjutnya melakukan analisa data dengan (content analysis). Dari setiap variabel dan sub variabel diidentifikasikan sesuai dengan analisis kebijakan versi Patton \& Savicky. ${ }^{18}$

Setelah itu dilakukan validitas data dengan melakukan triangulasi sumber dengan cross check dengan sumber lain, triangulasi metode dengan melakukan pengumpulan data wawancara mendalam dengan informan dan telaah dokumen kebijakan, dan triangulasi data melakukan cross chek dengan data yang ada. Setelah itu dilakukan validitas data dengan melakukan triangulasi sumber dengan cross check dengan sumber lain, triangulasi metode dengan melakukan pengumpulan data wawancara mendalam dengan informan dan telaah dokumen kebijakan, dan triangulasi data melakukan cross chek dengan data yang ada.

Setelah itu dilakukan validitas data dengan melakukan triangulasi teori yaitu dengan mengecek kebenaran temuan atau data dengan teori terkini, triangulasi data dengan 
membandingkan atau megecek balik derajat kepercayaan suatu informasi atau data yang diperoleh melalui wawancara dengan data sekunder berupa dokumen-dokumen terkait, triangulasi sumber, dengan mengkonfirmasi kebenaran temuan atau data kepada beberapa informan.

Analisa tema dalam penelitian ini adalah mencakup 5 tema penelitian yaitu 1) Ketersediaan anggaran dan fasilitas, 2) Sumber Daya, 3) Wewenang, Sasaran dan Mutu kebijakan pelaksanaan SMS Gateway, 4) SOP rujukan dan 5) Implementasi dan Standar Kebijakan Operasional SMS Gateway.

\section{HASIL PENELITIAN}

\section{Ketersediaan Anggaran}

Berdasarkan hasil wawancara, diketahui bahwa Dinas Kesehatan Kabupaten Cirebon belum mencukupi ketersediaan tenaga PONED secara kuantitatif berdasarkan standar Kepmenkes No. 1051 Tahun 2008. Selain itu, Puskesmas juga masih memiliki petugas PONED yang belum mengikuti pelatihan pengelolaan SMS Gateway. Tetapi, informan menjelaskan bahwa syarat menjadi petugas PONED adalah harus memiliki latar belakang pendidikan yang mendukung PONED dan punya pengalaman dibidang IT. Kemudian, wewenang petugas SMS Gateway Dinas Kesehatan Kabupaten Cirebon berbeda-beda dan terdapat petugas SMS Gateway yang melaksanakan tugas di luar bidang tugas pokok dan fungsinya (tupoksi). Selain itu, penanggung jawab SMS Gateway memiliki otoritas dalam mendelegasikan wewenangnya kepada residen, apabila penanggung jawab SMS Gateway tidak sempat memberikan pelayanan kepada pasiennya. Petugas SMS Gateway sebenarnya mengetahui adanya alokasi anggaran khusus SMS Gateway, tetapi mereka tidak mengetahui berapa besar alokasi anggaran tersebut. Selain itu, ada informan yang menjelaskan bahwa ketersediaan anggaran SMS Gateway diperolah dari APBN (Anggaran Pendapatan Belanja Negara) Kementerian Kesehatan dalam bentuk Dana Alokasi Khusus (DAK).

Berdasarkan hasil wawancara mendalam dengan para informan diketahui bahwa sumber dana untuk pelaksanaan SMS Gateway sudah dianggarkan didalam RBA (Rencana Biaya Anggaran) setiap tahun, dan selanjutnya diusulkan ke pusat. Ketersediaan alokasi anggaran SMS Gateway bukan hanya dari kementerian kesehatan, tetapi ada juga dari anggaran operasional, yaitu anggaran Jampersal, Jamkesmas, maupun Jamkesda. Namun, anggaran operasional tersebut bisa digunakan kalau terdapat kebutuhan yang mendesak, sehingga penanggung jawab SMS Gateway harus menganggarkan kebutuhan tersebut dalam bentuk proposal.

Alokasi anggaran merupakan aspek sumber daya yang sangat mendukung kelancaran pelaksanaan suatu kebijakan, sebab tanpa alokasi anggaran, implementasi kebijakan tidak akan berjalan secara efektif. ${ }^{16}$ Jika alokasi anggaran tersedia, maka pelayanan SMS Gateway yang seharusnya diberikan kepada masyarakat juga tersedia, begitu pula sebaliknya. Oleh karena itu, kebutuhan sumber daya anggaran SMS Gateway akan mempengaruhi keberhasilan pelaksanaan kebijakan pelaksanaan SMS Gateway. Ketersediaan anggaran membuat disposisi para pelaksana kebijakan menjadi meningkat. Alokasi anggaran SMS Gateway pada dasarnya disediakan untuk memenuhi kebutuhan SMS Gateway berupa sarana dan prasarana, baik peralatan maupun non-peralatan. Jika di lihat dari pengetahuan petugas SMS Gateway, masih terdapat petugas SMS Gateway yang belum memahami mengenai kebijakan alokasi anggaran SMS Gateway. Hal ini perlu disampaikan karena alokasi anggaran yang dikeluarkan mempengaruhi pelayanan program SMS Gateway, sebab alokasi anggaran SMS Gateway yang sifatnya transparan/terbuka akan memudahkan petugas SMS Gateway dalam memberikan saran mengenai fasilitas yang kurang yang nantinya dapat memenuhi kebutuhan SMS Gateway di Puskesmas. 


\section{Sumber Daya (SDM dan Fasilitas)}

Kegiatan pelayanan di Puskesmas seperti halnya sebuah instansi dimana diperlukan managerial yang mampu merencanakan, mengorganisasikan, dan monitoring sumber daya untuk mencapai sasaran secara efektif dan efisien. Sistem pendukung pelaksanaan Pelayanan Obstetri Neonatal Emergensi Komprehensif (PONED) di Dinas Kesehatan Kabupaten Cirebon baik itu dari segi manajemen, SDM, pembiayaan, SOP, kebijakan direksi, sarana dan prasarana. Sarana penting sebagai pendukung berupa bank darah memang belum ada di Puskesmas ini, namun Puskesmas Kota Cirebon sudah menjalin kerjasama dengan PMI yang dibuktikan dengan adanya MOU saat observasi. Untuk sarana peralatan sudah sesuai dengan standar panduan SMS Gateway. Berdasarkan hasil analisis tema dan pemaparan keenam informan pada saat wawancara berlangsung didapatkan pandangan bahwa sumber daya manusia yang tersedia di Dinas Kesehatan Kabupaten Cirebon belum mencukupi.

Hasil wawancara, diketahui bahwa sumber daya manusia yang dibutuhkan dalam Pelaksanaan SMS Gateway di Dinas Kesehatan Kabupaten Cirebon masih belum mencukupi atau belum maksimal. Tetapi berdasarkan buku pedoman PONED jumlah SDM sudah memenuhi standar. Hasil wawancara dengan informan, peneliti menanyakan bahwa apa saja yang termasuk dalam sumber daya PONED melalui SMS Gateway, dan semua informan sudah memberikan informasi yang sama yaitu yang termasuk dalam sumber daya PONED adalah Dokter spesialis obgyn, dokter spesialis anak, dokter spesialis anastesi, perawat dan bidan.

Ketersediaan fasilitas seperti peralatan SMS Gateway telah mencukupi, tetapi peralatan yang ada di Puskesmas belum melengkapi semua kebutuhan yang diharapkan di Puskesmas PONED. Kemudian, terdapat beberapa peralatan yang belum difungsikan karena keterbatasan pengetahuan petugas dalam menggunakan peralatan tersebut.

Ada beberapa keluhan mengenai permasalahan pada sarana prasarana, yaitu koneksi internet yang kurang lancar, sehingga SMS rujukan terlambat masuk; alarm yang berbunyi terus menerus; aplikasi yang terkadang error yaitu tidak mendeteksi SMS baru yang masuk sehingga alarm tidak berbunyi; telepon kabel VK IGD yang tidak bisa dihubungi; dan handphone yang telah rusak. Untuk keadaan komputer, speaker, dan monitor masih dalam keadaan baik. Oleh karena hal tersebut, beberapa responden menyarankan pembaharuan sarana dan prasarana, yaitu penambahan wifi; penggantian handphone yang sudah rusak; telepon kabel yang langsung terhubung dengan ke VK IGD; penambahan titik SIJARIEMAS.

Hasil wawancara mendalam peneliti di ketahui bahwa fasilitas pendukung yang dibutuhkan dalam pelayanan SMS Gateaway di Dinas Kesehatan Kabupaten Cirebon sudah mencukupi. Hal ini telah dinyatakan oleh EA sebagai informan kunci, dan didukung oleh pernyataan informan lainnya yang juga menyatakan hal yang sama.

\section{Wewenang, Sasaran dan Mutu kebijakan pelaksanaan SMS Gateway}

Dinas Kesehatan Kabupaten Cirebon menyelenggarakan pelayanan obstetri dan neonatal yang bermutu melalui standarisasi Puskesmas PONED 24 Jam, dalam rangka menurunkan Angka Kematian Ibu dan Angka Kematian Bayi di Indonesia. Pelayanan yang bermutu ini dapat dipantau dan dinilai oleh Puskesmas itu sendiri melalui format yang telah disusun pada Standar Kinerja Manajemen dan Standar Kinerja Klinis

Petugas PONED telah mengetahui pelayanan Program SIJARIEMAS dan telah mampu membedakan pelayanan antara kebijakan pelaksanaan SMS Gateway di Puskesmas dengan Kebijaksanaan Pelaksanaan SMS Gateway yang ada di puskesmas. Beberapa informan memberikan gambaran mengenai alur proses pelayanan Program SIJARIEMAS pada saat pasien masuk atau di rujuk di Dinas Kesehatan Kabupaten Cirebon . Kemudian, terdapat tiga dari lima petugas PONED yang mengetahui tentang visi dan misi Program SIJARIEMAS di Puskesmas dan juga mengetahui tujuan didirikan Program SIJARIEMAS. 
Semua informan menyebutkan bahwa yang menjadi sasaran kebijakan pelaksanaan SMS Gateway adalah ibu hamil dan ibu dalam kondisi pasca melahirkan, baik rujukan maupun tanpa rujukan. Semua informan juga sudah mengetahui dan memahami cara dalam melaksanakan SOP.

Dinas Kesehatan Kabupaten Cirebon memberikan pelayanan SMS Gateaway kepada semua warga yang datang ke Puskesmas dan membutuhkan pelayanan SMS Gateaway dan mayoritas pasien rujukan yang mendapat pelayanan SMS Gateaway. Data sekunder yang diperoleh, secara keseluruhan yang menjadi sasaran utama adalah pasien rujukan dari puskesmas dan Puskesmas daerah, Jumlah rujukan di Dinas Kesehatan Kabupaten Cirebon tergolong tinggi dan mengalami peningkatan seiap tahun yaitu pada tahun 2010 berjumlah 394 rujukan ibu, tahun 2011 berjumlah 467 rujukan ibu dan tahun 2012 berjumlah 523 rujukan ibu.

\section{SOP Rujukan}

Penyelenggaraan PONED di Dinas Kesehatan Kabupaten Cirebon membagi pelayanan menjadi empat bagian, yaitu Pelayanan UGD/Kamar Bersalin, Pelayanan Perinatalogi, Pelayanan Nifas, dan Pelayanan OK/GSR, sehingga petugas PONED melakukan tanggung jawab sesuai dengan tugasnya masing-masing. Informan menjelaskan bahwa koordinasi setiap pelayanan SMS Gateaway dalam memberikan pelayanan kesehatan berjalan dengan konsisten dan jelas. Semua pelayanan yang ada di unit PONED saling berkoordinasi sesuai dengan prosedur dan kebutuhan pasien, misalnya koordinasi dengan Pelayanan Instalasi Laboratorium, Instalasi Radiologi, dan Unit Transfusi Darah. SOP PONED Puskesmas sudah berjalan dengan baik dan semua informan telah memahami SOP sehingga petugas PONED mampu melaksanakan tugas sesuai dengan prosedur tetap (protap) yang ada di unit PONED. Informan juga mengatakan bahwa terdapat beberapa SOP yang ada di unit PONED, yaitu SOP penerimaan dan penanganan, SOP pelayanan seperti SOP Perdarahan, SOP Partum, SOP Abortus, dan sebagainya. Tetapi, salah satu informan menjelaskan bahwa ketersediaan SOP pendelegasian wewenang masih dalam proses pembuatan surat keputusan (SK) direktur Puskesmas.

Peneliti menemukan adanya sebuah kemungkinan untuk tenaga kesehatan di Dinas Kesehatan Kabupaten Cirebon untuk melakukan tindakan yang kurang sesuai dengan SOP karena adanya sebuah alasan terkait sistem di Dinas Kesehatan Kabupaten Cirebon. Alasan lainnya karena disebabkan dengan angka rujukan dari beberapa puskesams PONED cukup tinggi. Hal ini bias dilihar dengan gambaran penyebaran pasien di sekitar Dinas Kesehatan Kabupaten Cirebon melalui peta kematian ibu karena keterlembatan rujukan.

Struktur organisasi yang dilaksanakan memiliki pengaruh yang signifikan terhadap implementasi kebijakan. Salah satu aspek struktur yang penting dari setiap organisasi adalah adanya SOP yang menjadi pedoman bagi setiap implementor yang bertindak dan fragmentasi yang memerlukan koordinasi. ${ }^{17}$ SOP yang baik bagi suatu organisasi pemerintah khususnya Puskesmas merupakan proses yang diberlakukan dalam organisasi pemerintah dalam melaksanakan kebijakan. SOP di Dinas Kesehatan Kabupaten Cirebon dalam melaksanakan kebijakan pelaksanaan SMS Gateway sudah ada, jelas, dan sesuai dengan tupoksi petugas PONED, sehingga tidak menghambat jalannya implementasi kebijakan ini. Petugas PONED di setiap bidang pelayanan sudah memahami dan menjalankan SOP sesuai dengan kebijakan Puskesmas, seperti SOP penerimaan dan penanganan dan SOP pelayanan lainnya, tetapi masih ada SOP yang masih menunggu SK direktur Puskesmas, seperti SOP pendelegasian wewenang yang masih belum dikeluarkan. Hal ini karena SOP pendelegasian wewenang merupakan salah satu standar Kepmenkes No. 1051 Tahun 2008 yang harus ada dalam penyelenggaraan PONED di Puskesmas. 


\section{Implementasi dan Standar Kebijakan Operasional PONED.}

Standar kebijakan pelaksanaan SMS Gateway Dinas Kesehatan Kabupaten Cirebon mengacu pada standar yang dikeluarkan pemerintah yakni Kepmenkes No.1051/Menkes/SK/XI/2008 tentang Pedoman Penyelenggaraan PONED 24 Jam di Puskesmas. dan masih terdapat kriteria-kriteria yang belum sesuai dengan standar.

Berdasarkan hasil wawancara mendalam diketahui bahwa standar ukuran yang digunakan dalam penyelenggaraan pelayanan obstetric neonatal emergency komprehensif mengacu kepada Permenkes. Dari perkembangan wawancara mendalam, peneliti menanyakan apakah panduan/acuan yang digunakan dalam melaksanakan keijakan PONED, dari hasil observasi peneliti juga diketahui bahwa RS sendiri sebenarnya selalu berusaha untuk mencapai nilai $100 \%$ dalam memberikan pelayanan. Dalam menjawab pertanyaan ini ditemukan perbedaan alasan antara informan kunci dengan informan yang lain, berikut penuturannya.

Hasil wawancara mendalam juga diketahui bahwa semua staf pelaksana PONED sudah mengerti standar yang menjadi indikator pelayanan SMS Gateaway dan baru-baru ini diadakan pelatihan PONED bagi SDM agar berkompeten sesuai standar prosedur. Seperti yang telah diketahui bahwa Puskesmas PONED 24 Jam adalah Puskesmas yang menyelenggarakan pelayanan kedaruratan maternal dan neonatal yang bertujuan untuk mengurangi Angka Kematian Ibu (AKI) dan Angka Kematian Bayi (AKB), dan mempunyai fungsi menangani kasus rujukan yang tidak mampu ditangani oleh petugas kesehatan di tingkat pelayanan primer (dokter, bidan, perawat). Seperti pada Teori Van Meter dan Van Horn bahwa para implementor harus mengetahui standar kebijakan, karena pengetahuan akan standar kebijakan, akan mempengaruhi kinerja pelayanan dalam pengimplementasian kebijakan program. ${ }^{19}$

Jika implementasi kebijakan ingin berhasil secara efektif dan efisien, maka para pelaksana kebijakan tidak hanya mengetahui apa yang harus dilakukan dan mempunyai kemampuan untuk melakukan kebijakan itu, tetapi mereka juga harus memiliki kemauan untuk melaksanakan kebijakan tersebut. Suatu organisasi kebijakan tentunya harus mengangkat pelaksana kebijakan sesuai dengan kriteria yang ditentukan agar implementasi kebijakan yang diinginkan tidak menimbulkan hambatan yang nyata. Oleh karena itu, komitmen pelaksana kebijakan harus memiliki dedikasi demi kepentingan masyarakat. Komitmen petugas PONED merupakan orang-orang yang memiliki sikap dedikasi dalam bekerja, seperti bekerja berdasarkan pembagian sift, bekerja dalam tim, dan kesediaan mematuhi aturan yang berlaku di Puskesmas khususnya untuk kebijakan pelaksanaan SMS Gateway, sehingga dapat dikatakan bahwa komitmen berjalan berdasarkan kriteria yang telah ditentukan oleh Puskesmas khususnya unit PONED.

\section{Merumuskan Analisis Kebijakan Pelaksanaan SMS Gateway di Dinas Kesehatan Kabupaten Cirebon}

Perumusan analisis rumusan kebijakan opearsional dalam penelitian ini mengacu pada konsep patton dan Savicky yang menggunakan enam langkah dalam merumuskan analisis kebijakan yang biasa disebut dengan A Basic Policy Analysis Process. Tahap-tahap penerapan Patton dan Savicky dalam penelitian ini dapat dijelaskan sebagai berikut :

\section{Langkah Pertama Mendifinisikan dan Mengidentifikasi Masalah}

Pada saat penelitian dilakukan, ditemukan beberapa faktor yang menyebabkan kurang optimal Pelaksanaan SMS Gateway:

1. Masalah dan hambatan yang dialami selama Pelaksanaan SMS Gateway adalah ketika dihari libur kesulitan dalam mencari tenaga dokter spesialis. Hambatan yang masih menjadi persoalan sampai dengan saat ini adalah sistem kesehatan dari pemerintah yang 
berbenturan dengan sistem didalam Puskesmas, menjadikan Dinas Kesehatan Kabupaten Cirebon tidak bisa memberikan pelayanan secara maksimal karena dibatasi oleh aturan dari pemerintah. Masalah adalah ketidak sesuaian yang signifikan dan tidak diinginkan antara standar kebersamaan dan kondisi nyata.

2. Belum adanya standar operasional yang jelas dalam pelaksanaan SMS Gateway di Dinas Kesehatan Kabupaten Cirebon. Dengan adanya SOP ini maka masalah kekurangan tenaga atau staf dalam melakukan pekerjaan yang kurang efektif dapat diminimalisir dengan adanya SOP tersebut.

3. Belum tersedianya pelayanan darah selama 24 jam, belum tersedianya pelayanan radiollogi selama 24 jam, dan belum tersedianya obat dan alat penunjang yang selalu ada saat dibutuhkan. Pelayanan darah di Dinas Kesehatan Kabupaten Cirebon saat ini masih dalam proses persiapan untuk pengoperasian karena masih menunggu surat izin operasional dari dinas kesehatan

4. Dana anggaran PONED untuk pengadaan alat hanya ada pada tahun 2012, sedangkan untuk tahun selanjutnya hanya ada anggaran untuk perbaikan alat. Namun besar anggaran untuk PONED di Dinas Kesehatan Kabupaten Cirebon tidak dapat diketahui, karena berrdasarkan hasil wawancara dengan Kepala Bidang Sarana dan Prasarana serta staf bagian perencanaan memberikan informasi bahwa anggaran untuk PONED tidak dirincikan secara khusus.

5. SDM yang masih terbatas. Pelaksanaan SMS Gateway di Dinas Kesehatan Kabupaten Cirebon bukan hanya Tim PONED yang berperan dalam pelayanan khusus untuk PONED tapi semua dokter, perawat, dan bidan yang sedang bertugas dan apabila terdapat pasien emergensy akan melayani pasien sesuai dengan prosedur yang telah ditentukan.

6. Ketidakjelasan pesan komunikasi yang disampaikan di Dinas Kesehatan Kabupaten Cirebon berkenaan dengan implementasi kebijakan akan mendorong terjadinya interpretasi yang salah bahkan mungkin bertentangan dengan makna awal. Ketidakjelasan pesan komunikasi kebijakan tidak selalu menghalangi implementasi kebijakan pelaksanaan SMS Gateway.

Berdasarkan identifikasi masalah, maka peneliti mendapatkan temuan Analysis of Policy dan Analysis for Policy tentang pelaksanaan kebijakan SMS Gateway. Adapun temuan tersebut dapat dilihat pada tabel berikut:

Tabel 1. Analysis of Policy dan Analysis for Policy

\begin{tabular}{lll}
\hline \multicolumn{1}{c}{ Analysis of Policy } & \multicolumn{2}{c}{ Analysis for Policy } \\
\hline $\begin{array}{l}\text { Belum adanya standar prosedur operasional yang } \\
\text { mengatur rujukan kegawat darurat maternal dan } \\
\text { neonatal }\end{array}$ & $\begin{array}{l}\text { Adanya rumusan alternatif kebijakan yang mengatur } \\
\text { sistem rujukan kegawat darurat maternal dan } \\
\text { neonatal }\end{array}$ \\
\hline $\begin{array}{l}\text { Pelaksanaan kebijakan SMS Gateway belum } \\
\text { dilaksanakan secara optimal }\end{array}$ & $\begin{array}{l}\text { Merumuskan kebijakan peningkatan sumber daya } \\
\text { manusia dalam sistem rujukan kegawat darurat } \\
\text { maternal dan neonatal }\end{array}$ \\
\hline $\begin{array}{l}\text { Dana anggaran PONED untuk pengadaan alat hanya } \\
\text { ada pada tahun 2012, sedangkan untuk tahun } \\
\text { selanjutnya hanya ada anggaran untuk perbaikan alat }\end{array}$ & $\begin{array}{l}\text { Merumuskan kebijakan peningkatan sumber daya } \\
\text { maternal dan neonatal }\end{array}$ \\
\hline $\begin{array}{l}\text { Belum adanya MOU sehingga pesan komunikasi } \\
\text { yang disampaikan di Dinas Kesehatan Kabupaten }\end{array}$ & $\begin{array}{l}\text { Adanya sarana dan prasarana yang lengkap guna } \\
\text { mendukung kebijakan SMS Gateway }\end{array}$ \\
$\begin{array}{l}\text { Cirebon berkenaan dengan implementasi kebijakan } \\
\text { tidak dapat dipahami oleh fasilitas kesehatan }\end{array}$ & \\
\hline
\end{tabular}


Tabel 2. Strategi SWOT

\footnotetext{
STRATEGI SO

Ciptakan strategi yang menggunakan kekuatan untuk memanfaatkan peluang:

1. Mengoptimalkan ketersediaan anggaran dapat diiringi dengan alokasi anggaran yang transparan

2. Petugas PONED dapat melaksankan protap sebaik mungkin dengan adanya reward yang memadai

3. Petugas PONED dapat menjalan SIJARIEMAS sesuai program pembaharuan yang ada

4. Meningkatkan evaluasi internal melalui audit maternal dan neonatal dengan adanya koordinasi yang baik antar unit
}

\section{STRATEGI WO}

Ciptakan strategi yang meminimalkan kelemahan untuk memanfaatkan peluang:

1. Membuat SOP SMS Gateway dalam rujukan kegawatdaruratan maternal untuk semua unit kesehatan

2. Melengkapi fasilitas dalam program rujukan maternal

3. Optimalkan jumlah staf dalam menjalankan kebijakan sistem rujukan

4. Memaksimalkan peralatan yang dimiliki dalam melaksanakan kebijakan sistem rujukan

5. Optimalkan insentif/reward kepada kader

\section{STRATEGI ST}

Ciptakan strategi yang menggunakan kekuatan untuk mengatasi ancaman :

1. Optimalkan ketersediaan anggaran dapat diiringi dengan alokasi anggaran yang transparan untuk mengatasi permasalahan keterlambatan rujukan

2. Berikan kesempatan petugas PONED untuk dapat melaksanakan protap sebaik mungkin

3. Petugas PONED dapat menjalan SIJARIEMAS sesuai program pembaharuan yang ada untuk mengatasi aplikasi yang error

4. Melakukan koordinasi untuk mengevaluasi internal melalui audit maternal dan neonatal dengan

\section{STRATEGI WT}

Ciptakan strategi yang meminimalkan kelemahan dan menghindari ancaman :

1. Membuat SOP SMS Gateway dalam rujukan kegawatdaruratan maternal untuk semua unit kesehatan untuk mengatasi keterlambatan rujukan

2. Lengkap fasilitas dalam program rujukan maternal

3. Memberikan pelatihan kepada petugas untuk menggunakan peralan dengan baik

4. Memeriksa peralatan secara bereksinambungan untuk mengatasi jaringan yang error

5. Meningkatkan kinerja petugas untuk mengatasi koneksi internet

\section{Langkah Ketiga Mengindentifikasi Alternatif Kebijakan}

Berdasarkan strategi alternatif kebijakan untuk mengatasi masalah yang telah dikemukakan sebelumnya dalam pelaksanaan kebijakan penggunaan SMS Gateway pada rujukan kegawatdaruratan maternal di Dinas Kesehatan Kabupaten Cirebon ada empat alternatif, yaitu :

1. Alternatif I : Pembuatan SK Kepala Dinas tentang Pelaksanaan SMS Gateway Rujukan Gawat Darurat Maternal di Kabupatan Cirebon

2. Alternatif II : Pembuatan Standar Operasional Prosedur SMS Gateway Rujukan Gawat Darurat Maternal

3. Alternatif III : Pembuatan MOU dalam pelaksanaan SMS Gateways dalam di Dinas Kesehatan Kabupaten Cirebon.

4. Alternatif IV : Peningkatan SDM sesuai dengan kebutuhan pelaksanaan SMS Gateways

\section{Langkah Keempat Menampilkan Identifikasi Alternatif Kebijakan Operasional}

Berdasarkan identifikasi alternatif kebijakan operasional yang menjadi prioritas adalah pembuatan SK dan SOP tentang standar prosedur SMS Gateways dalam rujukan gawat darurat maternal. Adapun rumusan alternatif kebijakan tersebut adalah sebagai berikut:

1. Alternatif I : Draft SK Kepala Dinas tentang Standar Prosedur SMS Gateway Rujukan Gawat Darurat Maternal di Kabupatan Cirebon 
Sebagaimana uraian sebelumnya bahwa kebijakan pelaksanaan SMS Gateway di wilayah Kabupaten Cirebon sudah dilaksanakan namun belum optimal, salah satunya belum adanya SOP. Adapun draft SK Kabupaten Cirebon untuk pembuatan SOP.

2. Alternatif II : Membuat Standar Prosedur SMS Gateway Rujukan Gawat Darurat Maternal Prosedur merupakan suatu rangkaian metode yang telah menjadi pola tetap dalam melakukan suatu pekerjaan yang merupakan kebulatan. Sementara itu, standar prosedur operasional diartikan sebagai urutan langkah-langkah yang berkaitan dengan tujuan yang akan dicapai dalam penyusunan standar prosedur operasional. Perlunya membuat alternatif prosedur SMS Gateway rujukan gawat darurat maternal dan neonatal, hal ini dalam rangka mengoptimalkan pelaksanaan kebijakan SMS Gateway di wilayah Dinas Kabupaten Cirebon. Adapun alasan peneliti mengajukan alternatif ini untuk membuat agar terjadi kesinambungan antara fasilitas kesehatan dengan tenaga kesehatan dokter atau bidan pelaksana serta untuk meningkatkan kepuasan pelayanan kesehatan pada umumnya dan secara khusus pelayanan kesehatan gawat darurat maternal neonatal kepada masyarakat di fasilitas kesehatan. Adapun alternatif standar prosedur operasionalnya.

\section{PEMBAHASAN}

Alternatif kebijakan yang diajukan yaitu ada dua, yang pertama membuat SK Kepala Dinas tentang petunjuk teknis sistem SMS Gateways rujukan pelayanan kesehatan dan kedua adalah Standar Prosedur SMS Gateway Rujukan Gawat Darurat Maternal dan. SK dan SOP terpilih sebagai alternatif yang dibutuhkan dalam mengatasi masalah pelaksanaan kebijakan

SMS Gateway Rujukan Gawat Darurat Maternal. Tujuan pembuatan SOP adalah untuk menjelaskan perincian atau standar yang tetap mengenai aktivitas pekerjaan yang berulangulang yang diselenggarakan. SOP yang baik adalah SOP yang mampu menjadikan arus kerja yang lebih baik, menjadi panduan, penghematan biaya, memudahkan pengawasan, serta mengakibatkan koordinasi yang baik antara satu fasilitas kesehatan dengan fasilitas kesehatan lainnya.

SOP disusun harus memenuhi prinsip-prinsip antara lain: ${ }^{20}$

1. Konsisten. SOP harus dilaksanakan secara konsisten dari waktu ke waktu, oleh siapapun, dan dalam kondisi apapun.

2. Komitmen. SOP harus dilaksanakan dengan komitmen penuh dari seluruh petugas kesehatan dan juga keluarga pasien.

3. Perbaikan berkelanjutan. Pelaksanaan SOP harus terbuka terhadap penyempurnaanpenyempurnaan untuk memperoleh prosedur yang benar-benar efisien dan efektif.

4. Mengikat. SOP harus mengikat pelaksana dalam melaksanakan tugasnya sesuai dengan prosedur standar yang telah ditetapkan.

5. Seluruh unsur memiliki peran penting. Seluruh petugas kesehatan peran-peran tertentu dalam setiap prosedur yang distandarkan. Jika pegawai tertentu tidak melaksanakan perannya dengan baik, maka akan mengganggu keseluruhan proses, yang akhirnya juga berdampak pada proses pencegahan dan pengendalian infeksi.

6. Terdokumentasi dengan baik. Seluruh prosedur yang telah distandarkan harus didokumentasikan dengan baik, sehingga dapat selalu dijadikan referensi bagi setiap mereka yang memerlukan.

Dengan adanya SOP maka permasalahan pelaksanaan kebijakan dalam rujukan gawat darurat maternal dengan SMS Gateways dapat teratasi. Hal ini karena SOP itu sendiri dibuat untuk mempermudah langkah-langkah penerapan SMS Gateways baik di Bidan Praktek Mandiri (BPM), Puskesmas PONED, Puskesmas Non PONED, Klinik Bersalin dan Rumah Sakit serta Dinas Kesehatan.

SK diperlukan untuk lahirnya SOP. Adanya SK dan SOP, maka kolaborasi antar fasilitas baik publik maupun swasta diharapkan akan membentuk suatu jejaring sistem 
rujukan pelayanan kegawatdaruratan ibu dan bayi baru lahir/neonatus di dalam suatu wilayah tertentu termasuk di Kabupaten Cirebon. Di tingkat Kabupaten terdapat 3 tingkat kemampuan pelayanan kegawatdaruratan ibu dan bayi baru lahir, yaitu:

1. Rumah Sakit PONEK (Pedoman RS PONEK dan RSIA)

2. Puskesmas PONED (Pedoman Puskesmas PONED)

3. Bidan di Desa atau BPM yang mampu memberikan PPGDON (Pedoman PPGDON).

Agar dapat terbangun suatu jejaring sistem rujukan yang efektif dan efisien, maka antar pemberi layanan di semua fasilitas yang telah berjejaring seyogyanya harus terjadi suatu pertukaran informasi yang tepat dan sama. Hal ini harus secara berkesinambungan disosialisasikan agar semua pemberi layanan dalam suatu jaringan bisa saling berkomunikasi dengan baik, tepat sasaran karena memiliki informasi dan pemahaman yang sama. Pertukaran informasi bisa berbentuk media cetak berupa surat, pedoman, leaflet, poster, buku saku maupun elektronik berupa SMS, email, atau dalam pertemuan, magang, pembinaan, pelatihan dan lain-lain.

SK dan SOP mengenai Rujukan Gawat Darurat Maternal dapat diterima oleh Dinas Kesehatan Kabupaten Cirebon dengan catatan disesuaikan dan diperbaiki sesuai dengan ketentuan yang berlaku. SK dan SOP ini diperlukan di lingkungan Dinas Kesehatan Kabupaten Cirebon sesuai dengan temuan yang ada dalam penelitian ini, sehingga diharapkan dengan adanya SOP maka permasalahan mengenai masalah kegawatdaruratan ini dapat teratasi dengan baik.

Kedua alternatif kebijakan yang dimunculkan yaitu membuat Draft SK Kepala Dinas tentang petunjuk teknis sistem SMS Gateways rujukan pelayanan kesehatan dan membuat Standar Operasional Prosedur SMS Gateway Rujukan Gawat Darurat Maternal setelah didiskusikan dengan pihak Dinas Kesehatan Kabupaten Cirebon hasilnya dapat diterima, namun dalam pelaksanaanya nanti perlu dilakukan pemantauan dan penyesuaian kebijakan yang sudah ada.

Keuntungan dari alternatif kebijakan operasional yaitu berupa SK dan SOP diantaranya adalah:

1. Dengan adanya SK dapat memperjelas dan mempertegas terhadap mekanisme pelaksanaan rujukan kegawatdaruratan maternal di lingkungan Dinas Kesehatan Kabupaten Cirebon dan menjadi pegangan bagi unit kesehatan terkait yaitu Bidan Praktek Mandiri (BPM), Puskesmas PONED, Puskesmas Non PONED, Klinik Bersalin dan Rumah Sakit.

2. Melalui SK dapat memperkuat kebijakan SOP SMS Gateways yang diterapkan di wilayah Dinas Kesehatan Kabupaten Cirebon untuk dilaksanakan oleh unit kesehatan terkait yaitu Bidan Praktek Mandiri (BPM), Puskesmas PONED, Puskesmas Non PONED, Klinik Bersalin dan Rumah Sakit.

3. Melalui SOP SMS Gateways dapat memperjelas petugas kesehatan di lapangan dalam melaksanakan kebijakan SMS Gateway Rujukan Gawat Darurat Maternal.

Kosekuensi jika SOP ini diterima adalah Dinas Kesehatan Kabupaten Cirebon dan juga Bidan Praktek Mandiri (BPM), Puskesmas PONED, Puskesmas Non PONED, Klinik Bersalin dan Rumah Sakit harus melaksanakannya dalam menangani rujukan kegawatdaruratan maternal. 
STANDAR PROSEDUR OPERASIONAL SMS GATEWAY RUJUKAN KEGAWATDARURATAN MATERNAL DAN NEONATAL

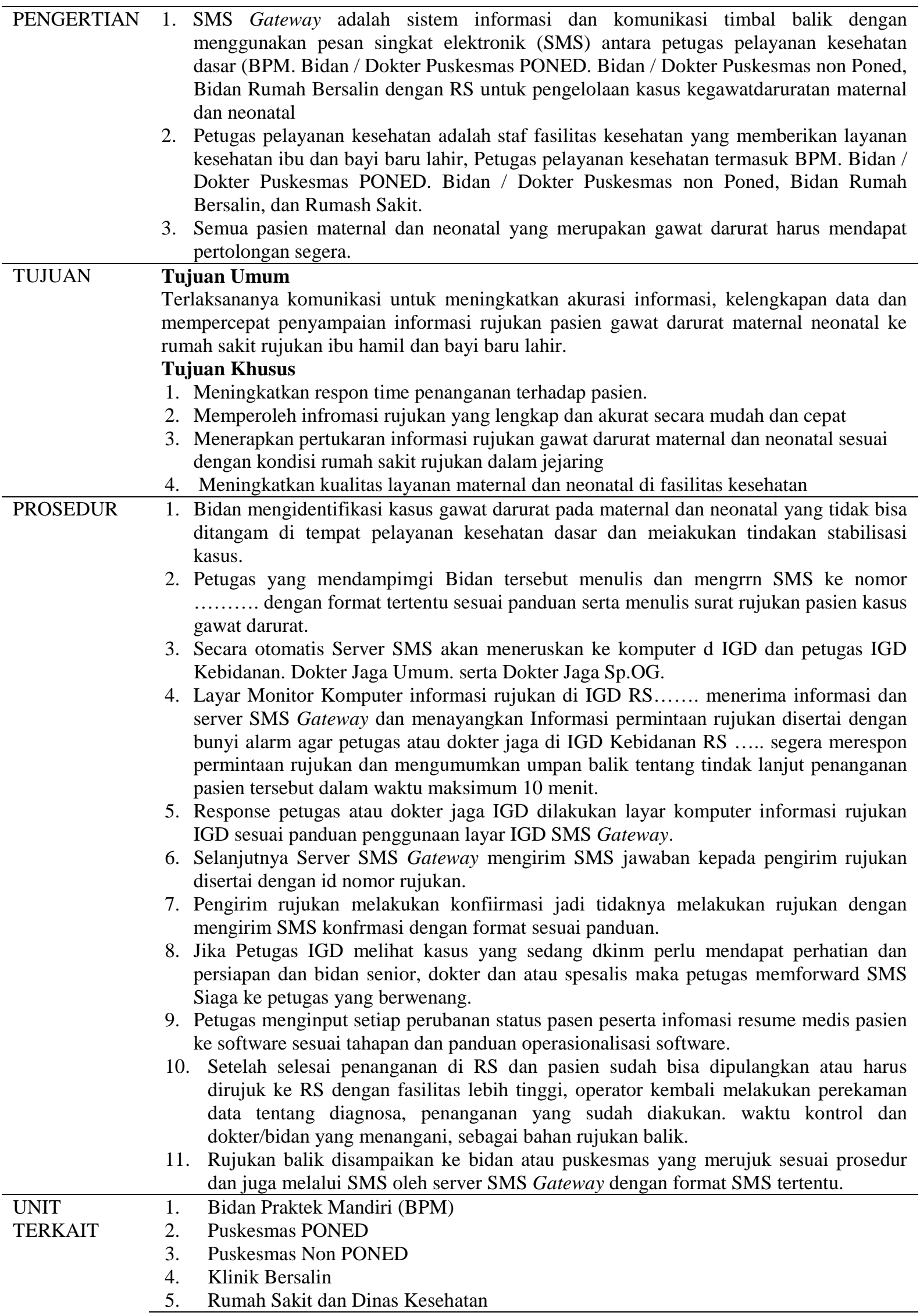




\section{KESIMPULAN}

Situasi pada pra rujukan kegawatdaruratan maternal menunjukkan bahwa SDM masih terbatas dengan kondisi jumlah staf yang terlibat dalam pelayanan SMS Gateway belum cukup, petugas yang telah diamanahkan dalam pelaksanaan SMS Gateway belum berperan aktif, petugas SMS Gateway belum memahami kebijakan alokasi anggaran SMS Gateway. Dari sarana dan prasarana menunjukkan bahwa peralatan yang tidak berfungsi sebagaimana mestinya sering mengalami error dan koneksi internet yang kurang lancar. Sedangkan dari ekonomi, ketersediaan alokasi anggaran SMS Gateway sudah mencukup karena bukan hanya dari kementerian kesehatan, tetapi ada juga dari anggaran operasional, yaitu anggaran Jampersal, Jamkesmas, maupun Jamkesda. Pada pelaksanaan dan operasional program penggunaan SMS Gateway pada rujukan kegawatdaruratan maternal yang menjadi faktor utama adalah SDM yang masih terbatas, jika pelaksanaan SMS Gateway sudah dilakukan secara bersamaan maka akan berdampak pada Pelaksanaan SMS Gateway yang tidak sesuai SOP sehingga tidak menimbulkan suatu angka kejadian kesakitan ataupun kematian yang tinggi pada ibu dan bayi. Kebijakan pelaksanaan SMS Gateway meliputi stabilisasi di UGD dan persiapan untuk pengobatan definitive. Penanganan kasus gawat darurat oleh tim PONED RS di ruang tindakan, rujukan dalam penanganan operatif cepat dan tepat meliputi laparatomi dan seksio sesaria, perawatan intermediate dan intensif ibu dan bayi dan pelayanan Asuhan Ante Natal Risiko Tinggi.

\section{SARAN}

Setelah dilakukan alternatif kebijakan operasional penggunaan SMS Gateway pada rujukan kegawatdaruratan maternal diharapkan petugas kesehatan dapat meningkatkan kualitas dan kompetensinya dalam melaksanakan kebijakan operasional penggunaan SMS Gateway dengan memahami dan mempelajari kembali SOP yang berlaku serta mengikuti kegiatan pendidikan dan pelatihan yang diselenggarakan oleh fasilitas kesehatan. Serta mempunyai kepercayaan terhadap kemampuan yang dimilikinya sehingga dapat melaksanakan kebijakan operasional penggunaan SMS Gateway pada rujukan kegawatdaruratan maternal.

\section{DAFTAR PUSTAKA}

1. WHO. World Health Report "Bridging the Gap". Geneva; 2012.

2. Kemenkes RI 2013. Profil Data Kesehatan Indonesia Tahun 2012. Jakarta: Kementerian Kesehatan Republik Indonesia; 2012.

3. Profil Kesehatan Indonesia. Depkes RI: Jakarta; 2011.

4. Abidin, Z.S. Kebijakan Publik, EdisiRevisi. Jakarta :Yayasan Pancur Siwah; 2002.

5. Dunn, W. N. Pengantar Analisis Kebijakan Publik, Yogyakarta : Gajah Mada University; 2000.

6. Adisasmito, Wiku. Buku Ajar Kebijakan Kesehatan. Jakarta: Departeman Administrasi dan Kebijakan Kesehatan, Fakultas Kesehatan Masyarakat Universitas Indonesia; 2006.

7. Afifah Tin \& Djajah Sarimawar. Pencapaian dan Tantangan Status Kesehatan Maternal di Indonesia. Jurnal Ekologi Kesehatan Vol 10. No.2 Tahun 2011.

8. Agus Dwiyanto. Manajemen Pelayanan Publik: Peduli, Inklusif dan Kolaboratif, Jogjakarta : Gadjah Mada University Press; 2010.

9. Agustino, Leo. Dasar-dasar Kebijakan Publik, Bandung :Alfabeta; 2008.

10. Rahmat, R. Hapsara, H. Pembangunan Kesehatan di Indonesia. Prinsip Dasar, Kebijakan, Perencanaandan Kajian Masa Depannya. Yogyakarta : Gadjah Mada University Press; 2004.

11. Subarsono, AG. Analisis Kebijakan Publik Konsep, Teori dan Aplikasi. Yogyakarta : Pustaka Pelajar; 2011. 
12. Suharto,E. Analisis Kebijakan Publik. Bandung : Alfabeta; 2008.

13. Effendy. Ilmu, Teori dan Filsafat Komunikasi. Bandung : PT. Citra. Aditya Bakti;2003

14. Agustino, Leo. Dasar-dasar Kebijakan Publik, Bandung :Alfabeta;2008

15. Afifah Tin \& Djajah Sarimawar. Pencapaian dan Tantangan Status Kesehatan Maternal di Indonesia. Jurnal Ekologi KesehatanVol 10. No.2 Tahun 2011: Jakarta;2011

16. Budiarto, Eko. Metodologi Penelitian Kedokteran : Sebuah Pengantar. Jakarta : EGC; 2002.

17. Ryanto, A. Pengolahan dan Analisis Data Kesehatan, Yogyakarta : Penerbit Mulia Medika; 2009.

18. Dunn, W. N. Pengantar Analisis Kebijakan Publik, Edisi Kedua, Yogyakarta : Gadjah Mada University Press; 2003.

19. Priyono dan Pranoko. Pemberdayaan : Konsep, Kebijakan dan Implementasi. Jakarta : CSIS; 2006.

20. Munijaya, A. A. Gde. Manajemen Kesehatan. Jakarta: Penerbit Buku Kedokteran; 2004. 